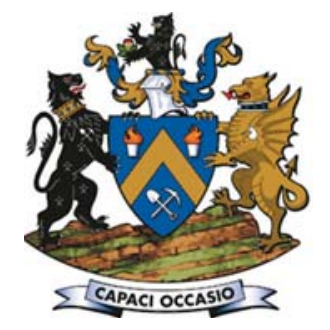

\title{
Structural characteristics of strata overlying of a fully mechanized longwall face: a case study
}

\author{
by J. Wang, J. Ning, L. Jiang, J-Q. Jiang, and T. Bu
}

\section{Synopsis}

In coal mining in China, the cutting height of the shearer in longwall faces is increasing. Owing to the increase of extraction height, the caved roof strata area is enlarged, and new issues are being encountered, such as determination of a suitable working resistance for the shield and control of the roof. Through field observation and theoretical analysis of the first longwall face with a height of $6.0 \mathrm{~m}$ in the Bayangaole mine, a three-stage structural model was developed. Stage I is defined as the period in which the lower immediate roof (LIR) caves into the goaf and is broken into irregular shapes of various sizes. Stage II is defined as the period in which the upper immediate roof (UIR) breaks and impacts the LIR. In stage III, the main roof breaks into blocks and then impacts the UIR. With respect to these three stages, a suitable method was identified for calculating the working resistance of the shield support for a super-great mining height longwall face (SGMHLW).

\section{Keywords}

Strata behaviour, strata movement, working resistance, super-great mining height longwall face.

\section{Introduction and background}

The coal seams in the Shendong coalfield, located in the northwest of China, are characterized by low dips and large thicknesses and are thus suited for full thickness extraction. Since the mid-1990s, the Shendong coalfield has been developed into one of the largest in the world (Ning, Liu, and Tan. 2014; Ning et al., 2017). Recent developments in mining equipment have made it possible extract entire seams up to $5.0 \mathrm{~m}$ thick in a single cut. This method, termed the 'super-great mining height longwall face' (SGMHLW) method, has been widely adopted in the Shendong coalfield (Table I) (Ju and $\mathrm{Xu}$, 2013; Peng, Li, and Zhou 2015; Zhang, Fan, and Ma 2011). According to some studies, sudden support-closure incidents often occur when using the SGMHLW method. The key to solving this engineering issue is to have a clear understanding of the structural characteristics and movement laws of the overlying strata. For instance, the load on the supports is related to the movement of the roof stratum as a response to the mining activities.

To date, extensive studies have been conducted to obtain a clear understanding of the mining-induced cave-in response of the strata (e.g. roof movement and failure responses). These studies have used different methods, such as numerical simulations, theoretical analyses, physical modelling, and on-site investigations (Ghose and Dutta, 1987; Yasitli and Unver 2005; Trueman, Lyman, and Cocker 2009; Shabanimashcool, Jing, and Li 2014; Tan, Li, and Ning 2017; Jiang, Sainoki, and Mitri 2017). Based on field observations, Peng and Chiang (1984) suggested that the first cave-in event involves shear fracture of the main roof before that of the face, while the subsequent and periodic cave-in events involve cantilever instead of Voussoir beam collapse. Song (1988) proposed that the rock blocks in the main roof stratum rotate and interlock with each other to form a jointed Voussoir beam when the stratum deflects downwards. Sofianos (1996) developed a model of Voussoir beams in the hard roof through numerical simulations. These studies indicated that roof cave-in is a dynamic process involving rock fracturing, disintegration, and movement. However, all these studies were conducted with a mining height of less than $6.0 \mathrm{~m}$, i.e. under normal mining height extraction conditions.

In recent years, considerable attention has been given to the strata failure and movement pattern induced by the mining of thick coal seams, for example, the longwall top coal caving (LTCC) and SGMHLW methods (Gong and Jin 2008; Yu, Zhao, and Kuang 2015; Yu, Zhao, and Xiao 2017). Owing to the high output and high efficiency of the SGMHLW method compared with the LTCC method at present, it is popular for mining thick coal

* State Key Laboratory of Mining Disaster Prevention and Control co-founded by Shandong Province and the Ministry of Science and Technology, Shandong University of Science and Technology, China.

(c) The Southern African Institute of Mining and Metallurgy, 2018. ISSN 2225-6253. Paper received Jul. 2017; revised paper received May 2018. 


\section{Structural characteristics of strata overlying a fully mechanized longwall face: a case study}

\begin{tabular}{|c|c|c|c|c|c|}
\hline Experimental site & Longwall face & Mining height (m) & Roof type & Mean roof load (kN) & References \\
\hline $\begin{array}{l}\text { Bayangaole mine } \\
\text { Bulianta mine } \\
\text { Bulianta mine } \\
\text { Halagou mine } \\
\text { Shangwan mine } \\
\text { Shangwan mine } \\
\text { Nalinmiaoer mine } \\
\text { Daliuta mine }\end{array}$ & $\begin{array}{c}311101 \\
22303 \\
32301 \\
22401-2 \\
51201 \\
12206 \\
62105 \\
22614\end{array}$ & $\begin{array}{l}6.0 \\
7.0 \\
6.1 \\
5.6 \\
5.3 \\
6.8 \\
6.2 \\
5\end{array}$ & $\begin{array}{l}\text { Medium hard } \\
\text { Soft and weak } \\
\text { Soft and weak } \\
\text { Soft and weak } \\
\text { Medium hard } \\
\text { Soft and weak } \\
\text { Soft and weak } \\
\text { Soft and weak }\end{array}$ & $\begin{array}{c}12782 \\
17612 \\
10022 \\
7587 \\
11856 \\
14652 \\
11207 \\
9176\end{array}$ & $\begin{array}{l}\text { This study } \\
\text { Ju et al. (2013) } \\
\text { Peng et al. (2015) } \\
\text { Peng et al. (2015) } \\
\text { Zhang et al. (2011) } \\
\text { Peng et al. (2015) } \\
\text { Peng et al. (2015) } \\
\text { Peng et al. (2015) }\end{array}$ \\
\hline
\end{tabular}

Note: Mean roof load was the shield support load at the onset of roof weighting

seams in China. Recently, a significant number of studies have been performed under SGMHLW extraction conditions. Literature reviews show that with the increase in extraction height, the mining-induced strata failure area is enlarged and the strata behaviour differs from that with a normal extraction height (Unver and Yasitli, 2009; Singh and Singh, 1999; Alehossein and Poulsen, 2010). Owing to complex geological conditions, roof fracturing, induced movements, and roof management are still unclear, in particular when the mining height is greater than $6.0 \mathrm{~m}$.

Determination of the shield capacity has been a research objective in many countries, resulting in a number of methods for its calculation (Coulthard, 1999; Verma and Deb, 2013; Lawson et al., 2017; Batchle,r 2017; Prusek, Płonka, and Walentek, 2017). As early as the 1980s, most researchers suggested that external loading on supports was related to the weight of the roof strata (Henderson, 1980). Currently, the determination of external loading on the shield supports is still a critical issue for roof management. There are four main methods for determining shield capacity: the detached roof block method, shield-leg pressure measurement method, design of powered support selection model, and yielding foundation model (Smart and Redfern, 1986; Gilbride, Richardson, and Agapito 1998; Trueman, Lyman, and Cocker, 2009; Islavath, Deb, and Kumar, 2016). All these methods have been commonly used by support manufacturers and coal operators. In summary, these theories and methods are used for calculating loads on shield supports based on the strata movement and failure responses induced by mining in a longwall face with a mining height less than $6.0 \mathrm{~m}$. The determination of shield support capacity is still challenging because of the limited understanding of the behaviour of the roof strata and of the mechanisms responsible for external support loading when the mining height is greater than $6.0 \mathrm{~m}$.

Owing to the limited studies, some issues, such as the movement of the overlying rock strata induced through the SGMHLW mining method and the unique formulae for determining external loadings on the supports, require more in-depth investigation and understanding. The present analysis is based on the mining conditions of panel 311101 in the Bayangaole Colliery, China. In this study, first, the time-weighted average resistance (TWAR) of the shield support was measured to understand the roof behaviour. Secondly, field observation was used to simulate the mining- induced overburden failures with the advance of the longwall face. Finally, a simplified theoretical model was established to describe the structural characteristics and movement of the roof. From these studies, a mathematical formula was developed to estimate the shield working resistance.

\section{Case study}

\section{Geology and geotechnical overview of Bayangaole Colliery}

The Bayangaole Colliery is located in the Shendong coalfield, Ordos City, Inner Mongolia Autonomous Region, China. The coal-bearing geological sequence has an average thickness of $730 \mathrm{~m}$ and contains eight coal seams, five of which can be mined with a total thickness of $24 \mathrm{~m}$. The mine is currently extracting seam No. 3 and all the panels in this mine are using the retreat longwall extraction method.

Panel 311101, at an average depth of $614 \mathrm{~m}$, was used as the target panel for this case study. As the first longwall face in the mining area of coal seam no. 3, Panel 311101 adopts the SGMHLW method. Its designed cutting height is $6.0 \mathrm{~m}$. The roof of the longwall face is supported by ZZ15000/16/25 standing-shield hydraulic supports with a rated working resistance of $15000 \mathrm{kN}$ (Figure 1). A total of 150 shield supports were used in this panel, and were numbered from 1 to 150 . Seam no. 3 has a mean thickness of $6.0 \mathrm{~m}$ and a mean dip angle of $1.5^{\circ}$, ranging from $0^{\circ}$ to $3^{\circ}$. The panel is approximately $260 \mathrm{~m}$ along the dip, and $2550 \mathrm{~m}$ along the strike. The simplified stratigraphic column of this panel, obtained by core logging, is shown in Figure 2. The roof

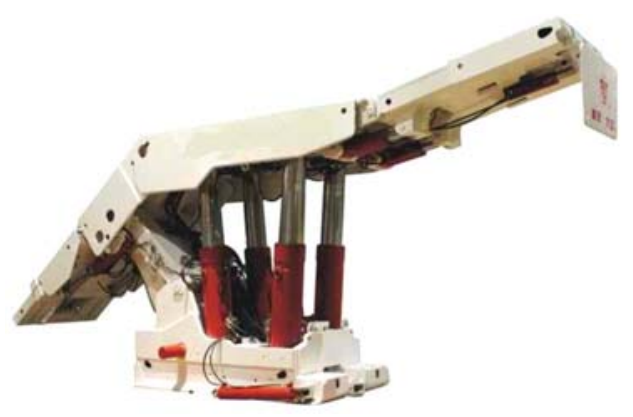

Figure 1-Shield type ZZ15000/16/25 used at the Bayangaole mine 


\section{Structural characteristics of strata overlying a fully mechanized longwall face: a case study}

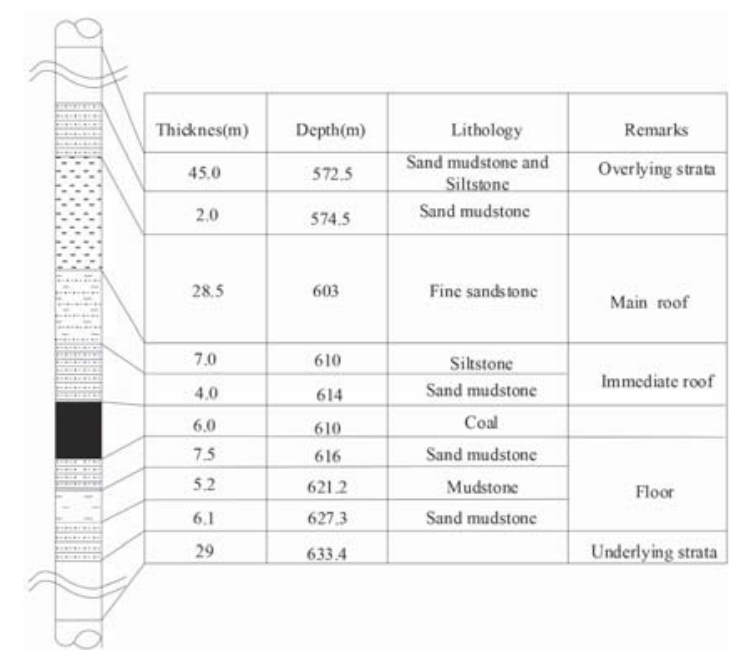

Figure 2-Typical geological column

strata are composed mainly of sandy mudstone, fine sandstone, and siltstone; these have a mean uniaxial compressive strength (UCS) of over $30 \mathrm{MPa}$. The floor is mainly sandy mudstone, with a mean UCS of $45 \mathrm{MPa}$. The overburden rocks are designated as medium-strong type.

\section{Field monitoring of the time-weighted average resistance of shield supports}

\section{Field monitoring methodology}

To measure the shield leg pressures from shield to shield and cycle to cycle, a real-time shield-leg pressure monitoring system (SLPMS) was utilized, as shown in Figure 3. This
SLPMS was produced by UROICAC Ltd., China. It consists of a host, control computer, data line, power supply equipment, and substation, among other components. The analysis software was installed on the control computer software to automatically calculate the TWAR of the shield supports and record the shield-leg pressures at one-minute intervals.

\section{Field monitoring analysis}

To simplify the analysis, this paper illustrates one case (shield leg pressures of the shield support no. 100) to describe the change rule of shield leg pressures. Figure 4 shows the recorded shield leg pressures of the shield support no. 100 when the longwall face advanced 20 and $60 \mathrm{~m}$. As shown in Figure 4, when the longwall face advanced $20 \mathrm{~m}$ (the nonweighting period), the shield leg load was approximately $7500 \mathrm{kN}$. However, when the longwall face advanced $60 \mathrm{~m}$ (weighting period begins), the shield leg load reached the early warning value of $12000 \mathrm{kN}$. It can be deduced that the load on the shield support increased considerably because of the beginning of the weighting period. In the figure, the early warning value was set according to engineering experience (in Table I). During the period marked 'overhaul' the longwall face did not advance because of faulty equipment.

$$
P_{i}=\frac{\sum P_{i} t_{i}}{T_{\mathrm{t}}}
$$

where $P_{t}$ is the average support resistance during period $t_{i}$, and $T_{t}$ is the time that a mining (supporting) cycle takes.

Figure 5 shows a typical support leg resistance variation in a mining cycle. In an earlier study by Peng (2015), Equation [1] was used to calculate the TWAR. Figure 6 shows the TWAR for a face advance distance of $500 \mathrm{~m}$. As

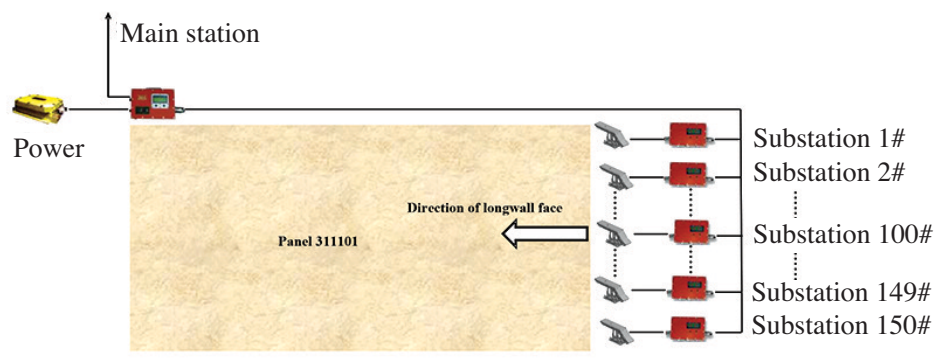

(a) Field layout of SLPMS

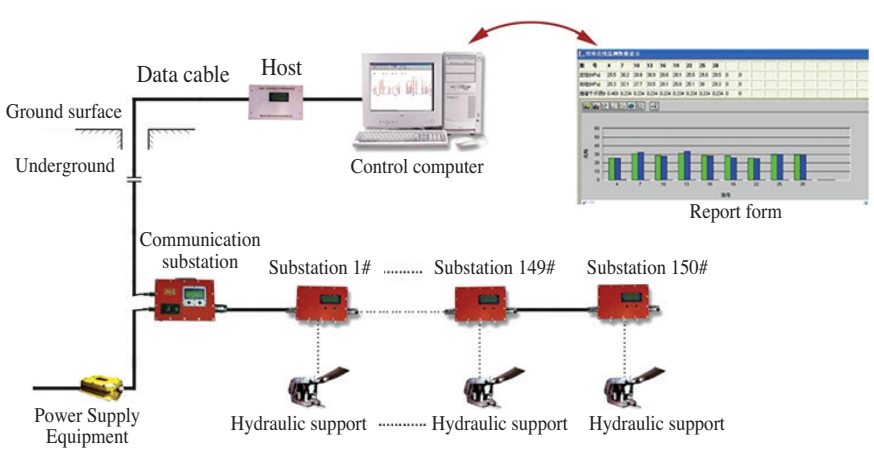

(b) Full profile of SLPMS 


\section{Structural characteristics of strata overlying a fully mechanized longwall face: a case study}

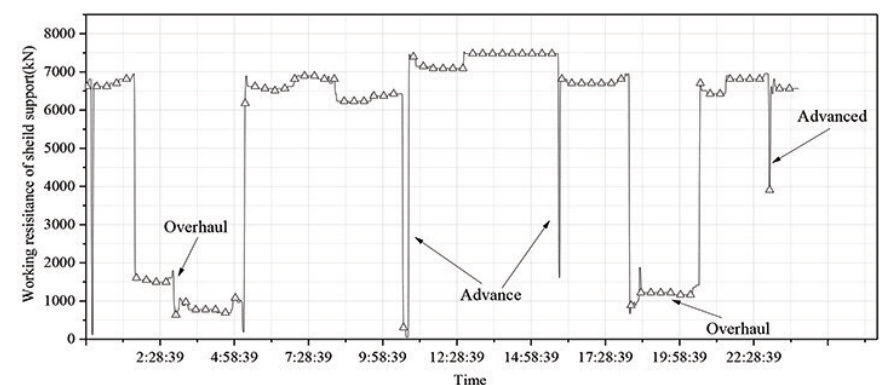

(a) Longwall face advanced $20 \mathrm{~m}$

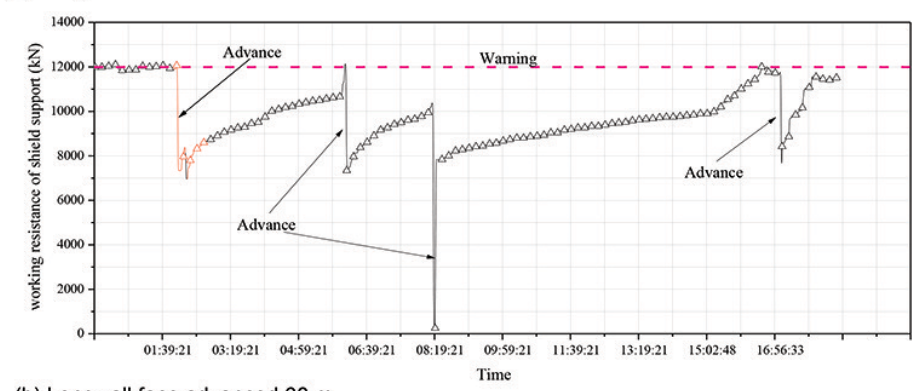

(b) Longwall face advanced $60 \mathrm{~m}$

Figure 4-Pressure change in shield supporting cycle

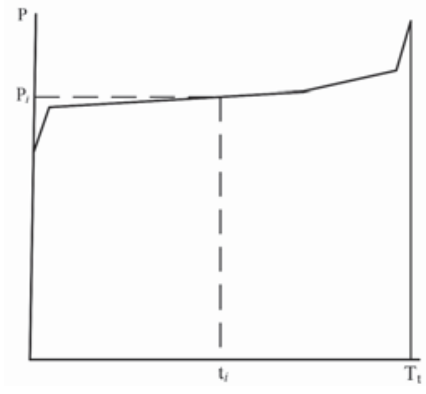

Figure 5-Calculation of TWAR in a mining cycle

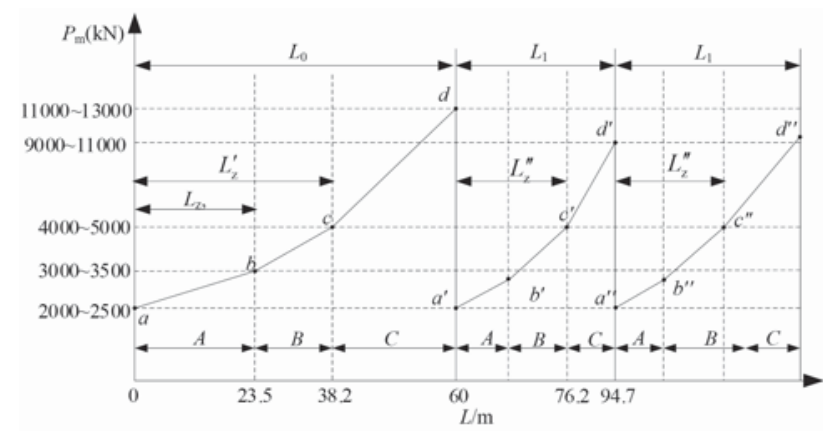

Note: $L_{0}$ is first weighting interval of main roof; $L_{1}$ is periodic weighting interval of main roof, $L$ is the distance longwall face advances.

Figure 6-Variation of TWAR measured by SLPMS

the longwall face advances, three stages are observed, distinguished by changes in the slope of the curves. These stages correspond to stages in the movement of the roof strata. In the following text, these three stages are named A, $\mathrm{B}$, and $\mathrm{C}$. At stage $\mathrm{A}$, along curves $\mathrm{ab}, \mathrm{a}^{\prime} \mathrm{b}^{\prime}$, and $\mathrm{a}^{\prime \prime} \mathrm{b}^{\prime \prime}$, the TWAR increases slowly, and its maximum value is $3000-3$ $500 \mathrm{kN}$. At stage B, along the curves bc, b'c', and b"c", the TWAR increases rapidly, and its maximum value is $4000-5$
$000 \mathrm{kN}$. Interestingly, at stage $\mathrm{C}$, along the curves $\mathrm{cd}, \mathrm{c}^{\prime} \mathrm{d}$, and $c$ "d" the TWAR shows the greatest increase: the increment is $7000-9000 \mathrm{kN}$ and is at least twice as large as that in the other stages. The in situ measurements demonstrated that the dynamic load coefficient (DLF: the ratio of shield-leg pressure during the nonweighting period to the shield leg pressure during the weighting period (Ju and $\mathrm{Xu}, 2013$ ) presented a periodic alternation between short/gentle and long/strong, and stage $\mathrm{C}$ was accompanied by a large DLF, up to 2.5 , which indicated a violent movement of the overburden.

\section{Field monitoring of longwall mining-induced strata movement}

A deep hole multiposition extensometer (DMPX), produced by UROICAC Ltd., China, was used to identify the longwall mining-induced strata movement. The DMPX is a specially constructed instrument that measures the different movements of selected overburdened strata layers in a borehole relative to a fixed point. In addition, a digital panoramic imaging device (DPID; UROICAC Ltd, China) was used to determine the longwall mining-induced strata failure. The DPID is a specially constructed instrument used for inspecting roof strata conditions, such as mining-induced macro-fractures, inside a borehole. These monitoring devices were also used by Ning et al. (2017) to investigate mininginduced overburden failures.

The DMPX was applied at a borehole, and four anchors were installed to monitor the overburden movement. Figure 7 shows the locations of the anchors. The displacement measured at the borehole with the advance of panel 311101 is shown in Figure 8. $H_{i}(i=1,2,3,4)$ is defined as the displacement of the rock strata at anchor $i$. The horizontal distances from panel 20107 to the boreholes is denoted as $D$, which is taken as negative when the working face does not advance across the location of boreholes and positive when 


\section{Structural characteristics of strata overlying a fully mechanized longwall face: a case study}

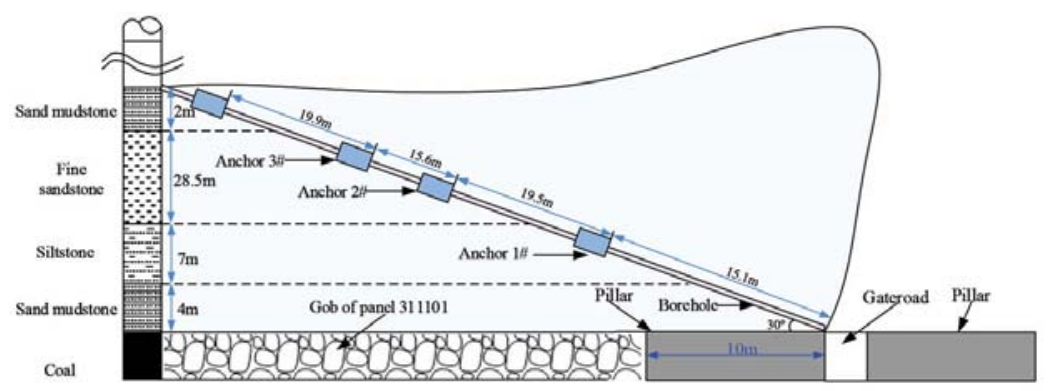

Figure 7-Illustration of layout for field investigation

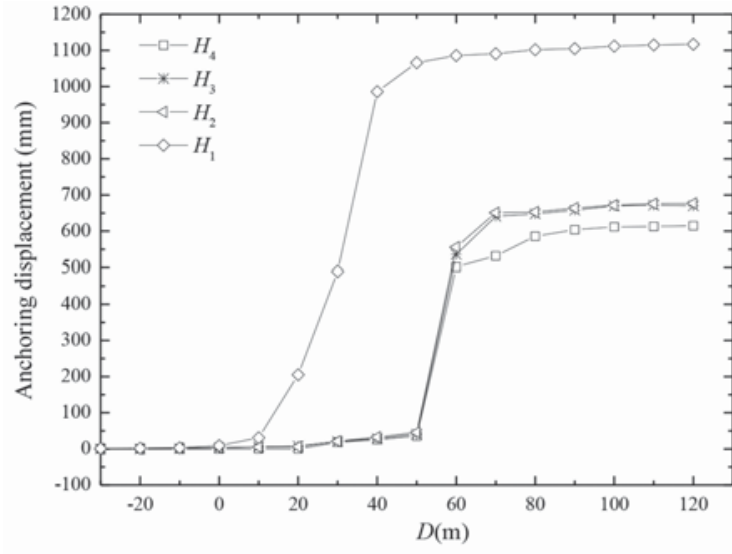

Figure 8-Overburden displacement with advancing longwall face

the working face advances across the location of boreholes. As shown in Figure 8, when $D=0 \mathrm{~m}<D<20 \mathrm{~m}$, the overlying strata were observed to move. When $D=38.2 \mathrm{~m}$, $H_{1}$ rapidly increased to $986 \mathrm{~mm}$, which was approximately one-sixth of the thickness of coal seam no. 3. This suggests that the strata monitored by anchor no. 1 moved as one unit. When $D=40<D<50 \mathrm{~m}, H_{2}, H_{3}$, and $H_{4}$ began to similarly increase. When $D$ was approximately $60 \mathrm{~m}, H_{2}, H_{3}$, and $H_{4}$ increased rapidly and reached a maximum of approximately 696,713 , and $709 \mathrm{~mm}$, respectively. This suggests that the strata monitored by anchors no. 2, 3, and 4 moved as one unit when the longwall face was approximately 40-60 m from the borehole.

The above analysis was validated through the monitoring of mining-induced macro-fractures (the DPID was used to measure the magnitudes of fractures, voids, and dislocations in the borehole wall). Figure 9a shows the fractures in the borehole wall recorded 7-8 $\mathrm{m}$ above the top of the coal seam for $D=40 \mathrm{~m}$. It could be deduced that when panel 311101 advanced $38.5 \mathrm{~m}$, the strata monitored by anchor no. 1 (fine sandstone) fractured. At this time, the working surface hydraulic support pressure increased, leading to roof weighting. This implies that the fracturing of fine sandstones led to roof weighting. Similarly, when $D=60 \mathrm{~m}$, fractures were observed in the borehole wall 15-41 $\mathrm{m}$ above the top of the coal seam (Figures $9 b-d$ ), indicating that the strata monitored by anchors no. 2, 3, and 4 were fractured as one unit. At this time, roof weighting also occurred.

\section{Summary of case study}

In brief, the field monitoring provided valuable and reliable data, indicating that the strata behaviour induced by SGMHLW is very violent and the dynamic load is much larger than when mining thinner seams. Owing to the considerable extraction height, the mining-induced strata failure area is enlarged and the progressive failure can be divided into different stages. This is described in the following sections.

\section{Simplified theoretical model of overlying strata structural characteristics}

To understand the progressive failure of the overlying roof induced by the SGMHLW operation, a simplified theoretical model was developed based on the field measurements and cantilever beams (Diederichs and Kaiser, 1999). Hereafter, model A represents the first occurrence of roof weighting and model B the subsequent periodic roof weighting.

\section{Structural characteristics of model $A$}

Based on the field measurements and theoretical research, the progressive failure of overlying strata in model A is divided into three stages:

> Stage I: In this stage, the lower immediate roof (LIR) caves into the goaf and is broken into irregular shapes of various sizes. LIR refers to the weak overlying layer which is located above the coal seam and has a similar thickness as the seam. As the longwall face advances from the set-up entry, the LIR bends and sags. When the face moves beyond the critical span of the LIR, it

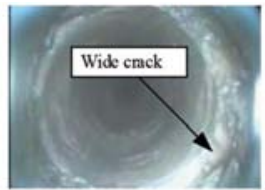

(a) $7.5 \mathrm{~m}$

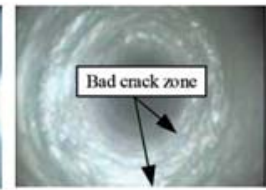

(b) $18 \mathrm{~m}$

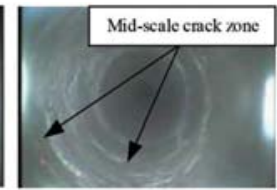

(b) $32.5 \mathrm{~m}$

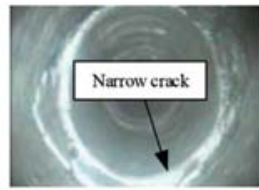

(b) $40.5 \mathrm{~m}$

Figure 9-Dislocations on the wall of borehole 


\section{Structural characteristics of strata overlying a fully mechanized longwall face: a case study}

breaks into fragments of different sizes and then caves into the goaf, as shown in Figure 10.

> Stage II: In this stage, the upper immediate roof (UIR) is broken and impacts the LIR. As the face continues to advance, the UIR sags downward. Once the longwall face moves beyond its critical span, the UIR is fractured and split into two rock beams (A and B), as shown in Figure 11. These two rock beams rotate with respect to each other to form a Voussoir beam above the minedout void. Owing to the large mining height, the panel void cannot be completely filled by the caved-in materials. The Voussoir beam continues to deflect downwards, ultimately resulting in a buckling failure. At that moment, rock beam B impacts the shield support via the LIR while rock beam A falls directly into the caved zone. The cave-in of the UIR involves similar processes to those in the conventional immediate roof that directly caved into the gob; however, it also involves instability before the balance of the Voussoir beam is broken. Owing to this special property, the dynamic impacts of the UIR cave-in event are harmful to the stability of the longwall shield supports.

> Stage III: In this stage, the main roof is broken into blocks and then impacts the UIR. Once the advancement of the working face has reached the critical span of the main roof (Figure 12), the first cave-in occurs as the main roof is broken into two rock beams owing to the occurrence of tensile fractures at its mid-span. When the main roof fractures, the broken roof beam quickly sags, generating dynamic impacts because of the large bed separation between the main roof and UIR. At this stage, owing to the impact force induced by the sudden sagging of the main roof, the longwall support load immediately increases, increasing the dynamic load coefficient. The caved height in the roof is the highest in the middle of the caved zone, where the panel void is fully filled by the caved-in materials.

\section{Structural characteristics of model B}

Field experience shows that after the first roof weighting, the longwall face enters into the second phase of overburden movement. In this phase, the main roof breaks periodically

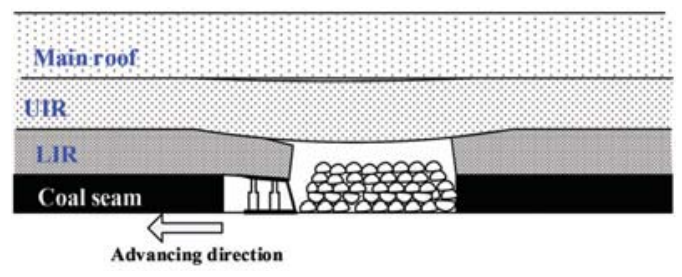

Figure 10-LIR: structural model A of SGMHLW at stage I

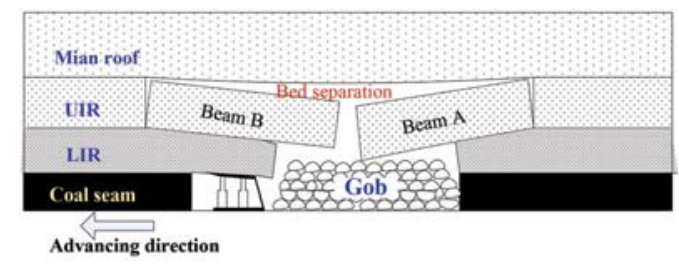

Figure 11-UIR: structural model A of SGMHLW at stage II behind the face after every critical advance so that a periodic weighting is placed on the longwall shields. The periodic cave-in is a progressive process which starts when the excavation reaches a critical length. During each occurrence of model B, the overburden movement can also be divided into three stages. During stage I, the LIR caves immediately behind the longwall supports. During stage II, the UIR hangs in the form of cantilever beams and is periodically broken at certain intervals. In stage III, shear fracture occurs in the main roof ahead of the face, and dynamic impacts are generated (Figure 13).

\section{Determination of working resistance for $6 \mathrm{~m}$ extraction height}

\section{Determination of working resistance from model $A$}

\section{Stage I}

At the beginning of stage I, both the LIR and main roof deform gently, and thus maintain stability. Then, the LIR caves into the goaf following the advance of the shield supports. Therefore, the LIR cannot maintain its selfsupporting stability. In this case, at least half of the LIR weight needs to be supported by the shield canopy (Ning et al., 2014). Consequently, the equation for calculating working resistance for stage I can be expressed as follows:

$$
P_{1}=\frac{m_{\mathrm{z}} \gamma_{\mathrm{z}} L_{\mathrm{z}}}{2 L_{\mathrm{k}}}
$$

where $m_{z}$ and $L_{z}$ are the thickness and critical span of the LIR (m), respectively, $\gamma_{z}$ is the unit weight of the LIR ( $\mathrm{kN.m}-3$ ), $L_{k}$ is the shield canopy length $(\mathrm{m})$, and $P_{1}$ is the calculated working resistance of the shield support for stage I.

\section{Stage /I}

At this stage, the main roof continues to deform gently and its movement has little influence on the UIR movement. Consequently, the force acting between the main roof and LIR can be ignored. Therefore, the roof load applied to the shield support is composed of two parts: the acting force on the support induced by the LIR, $Q_{1}$, and the impact load induced by the movement of the UIR, $Q_{2}$. As suggested by Song (1988), $Q_{1}$ can be expressed as follows:

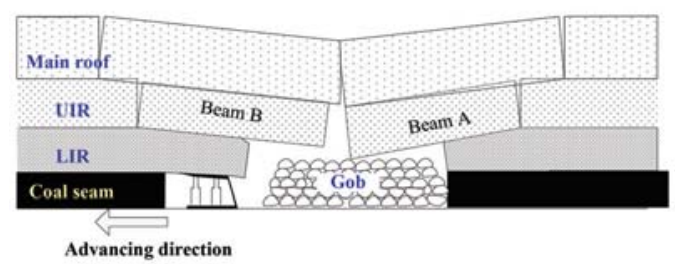

Figure 12-Main roof: structural model A of SGMHLW at stage III

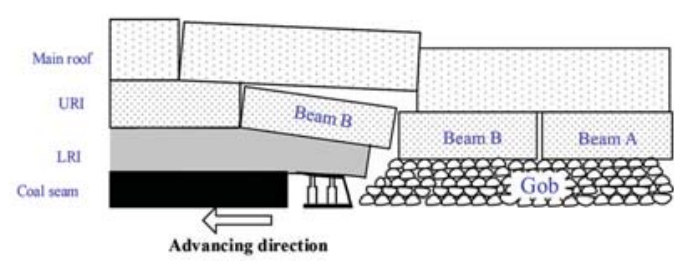

Figure 13-Structural model of stage III of model B 


\section{Structural characteristics of strata overlying a fully mechanized longwall face: a case study}

$$
Q_{1}=\frac{m_{z} \gamma_{z}\left(L_{\mathrm{s}}+L_{\mathrm{k}}\right)^{2}}{L_{\mathrm{k}}^{2}},
$$

where $L_{S}$ is the rear overhang of the LIR (m).

To identify the impact force induced by the movement of the UIR, $Q_{2}$, the yield foundation model was introduced. In this simplified model, the shield support is regarded as a spring (as shown in Figure 14). In Figure 14a, $o_{1}$ is regarded as the centre of gravity of beam B. $G_{B}$ and $G_{A}$ are regarded as the weight of beams B and A, respectively. Here, status A represents the beginning of the sagging of the UIR. Status B represents the occurrence of instability in the Voussoir beam. Moreover, once status B occurs, the LIR is suddenly impacted and the impact load is transferred to the longwall supports via the Voussoir beam. Status $C$ represents the end of impact in the LIR. Accordingly, in this study, we assumed that (i) at the time of statuses B and C, the velocity of the UIR tended to be zero; (ii) the UIR is regarded as a rigid body with vertical motion, and it transmits impact force to the shield support; (iii) the shield is regarded as a linear spring; and (iv) there is no energy dissipation during the UIR movement.

At statuses B and C, the UIR velocity is zero. Thus, the kinetic energy variation is also zero. The potential energy change of rock beam $\mathrm{B} \Delta E_{s p}$, UIR $\Delta E_{x p}$, and shield support $\Delta E_{v}$, can be expressed as follows:

$$
\begin{aligned}
& \Delta E_{\mathrm{sp}}=\frac{G_{\mathrm{B}} L_{\mathrm{z}}^{\prime} \Delta h_{0}}{4\left(x_{1}+L_{\mathrm{k}}\right)} ; \quad \Delta E_{\mathrm{xp}}=m_{\mathrm{z}} \gamma_{\mathrm{z}}\left(L_{\mathrm{s}}+L_{\mathrm{k}}\right) \Delta h_{0} \\
& \Delta E_{\mathrm{v}}=\frac{1}{2} F_{\mathrm{sd}} \Delta h_{0}
\end{aligned}
$$

where $G_{B}$ is the weight of the rock beam $B(\mathrm{kN}), \Delta h_{0}$ is the average displacement of the LIR covered by the shield canopy $(\mathrm{m}), \mathrm{x}_{1}$ is the horizontal distance from the UIR beam endfracturing to the longwall face, $L_{Z}^{\prime}$ is the first critical span of the UIR (m), and $F_{S d}$ is the impact force induced by the UIR movement $(\mathrm{kN})$.

At this stage, the potential energy of gravity is transformed into the elastic potential energy of the shield support. According to the energy conservation law (David, Robert, and Jearl, 2014), the relationship is written as follows:

$$
\Delta E_{\mathrm{xp}}+\Delta E_{\mathrm{sp}}=\Delta E_{\mathrm{v}}
$$

Based on Equations [4] and [5], the impact force induced by the UIR movement can be established as follows:
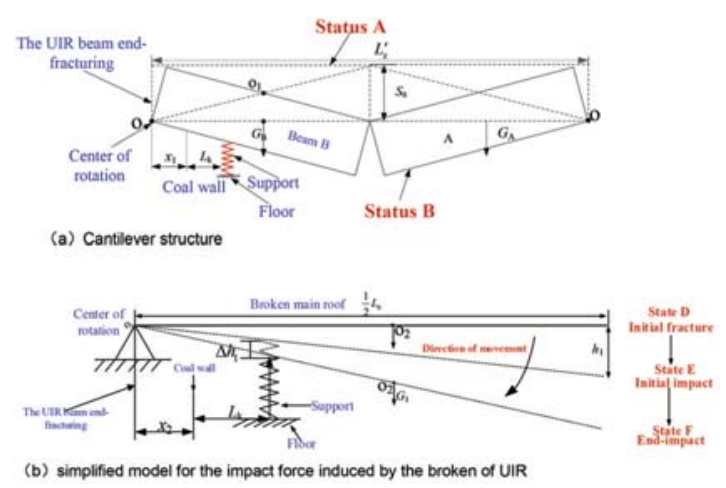

Figure 14-Model for calculation of UIR impact load at stage II of model A

$$
F_{\mathrm{sd}}=\frac{G_{\mathrm{B}} L_{\mathrm{z}}^{\prime}}{2\left(x_{1}+L_{\mathrm{k}}\right)}+2 m_{\mathrm{z}} \lambda_{\mathrm{z}}\left(L_{\mathrm{s}}+L_{\mathrm{k}}\right)
$$

The impact force transmitted to the shield support by the LIR can be expressed as follows:

$$
Q_{2}=\frac{m_{\mathrm{z}}^{\prime} \gamma^{\prime} L_{\mathrm{z}}^{\prime 2} \eta}{4\left(x_{1}+L_{\mathrm{k}}\right)}+2 \eta m_{\mathrm{z}} \gamma_{\mathrm{z}}\left(L_{\mathrm{s}}+L_{\mathrm{k}}\right)
$$

where $m_{z}^{\prime}$ is the UIR thickness $(\mathrm{m}), \gamma_{z}^{\prime}$ is the unit weight of the UIR ( $\mathrm{kN} . \mathrm{m}^{-3}$ ), and $\eta$ is the load transmitted coefficient, which can be obtained from Ning, Liu, and Tan (2014).

At this stage, when the LIR rotation reaches the maximum allowable sagging, the movement of the UIR induces the impact force, namely:

$$
m_{\mathrm{z}}^{\prime} \leq h-m_{\mathrm{z}}\left(K_{\mathrm{A}}-1\right)
$$

where $K_{A}$ is the bulk factor of the LIR.

At this stage, the shield support external load can be expressed as follows:

$$
P_{2}=Q_{1}+\frac{Q_{2}}{L_{\mathrm{k}}}
$$

\section{Stage III}

At this stage, the working resistance $P_{3}$ should be calculated from three factors: The first factor is the weight of the LIR, that is, $Q_{1}$; the second is load force induced by the UIR movement, that is, $Q_{3}$. The third is the impact force induced by the movement of the main roof, that is, $Q_{4}$. In this case, the weight of the LIR, $Q_{1}$, can be calculated using Equation [3]. The load force $Q_{3}$ induced by the movement of the UIR should be determined from two factors: one being the weight of the UIR over the shield canopy area, and the other the weight of the UIR overhangs. As suggested by Song (1988), $Q_{3}$ can be expressed as follows:

$$
Q_{3}=m_{\mathrm{z}}^{\prime} \gamma_{\mathrm{z}}^{\prime}\left(1+\frac{L_{\mathrm{s}}^{\prime}}{L_{\mathrm{k}}}\right)
$$

where $L_{S}^{\prime}$ is the rear overhang of the UIR (m).

To obtain the impact force $Q_{4}$ induced by the movement of the UIR, a simplified model was also developed (Figure 15). In this model, the broken main beam impacts the lower strata (the UIR and LIR are regarded as rigid bodies with vertical motion) rotating around point ' 0 '. In Figure $15,0_{2}$ is regarded as the centre of gravity of the broken beam. In Figure 15, state D represents the downward-deflected main roof and state E represents the occurrence of impact. State F represents the end of the main roof movement. At states $\mathrm{D}$ and $\mathrm{E}$, the velocities of the LIR, UIR, and main roof are zero. Therefore, at those states, the corresponding kinetic energy is zero.

After the main roof is broken at mid-span, the displacement of the roof over the shield canopy area increases by $\Delta h_{1}$. Here, the potential energy change of the main roof $\left(\Delta E_{\mathrm{jp}}\right)$, UIR $\left(\Delta E_{\mathrm{sp}}^{\prime}\right), \operatorname{LIR}\left(\Delta E_{\mathrm{xp}}^{\prime}\right)$, and shield support $\left(\Delta E_{\mathrm{V}}^{\prime}\right)$ can be expressed as follows:

$$
\begin{aligned}
& \Delta E_{\mathrm{jp}}=G_{1}\left(\frac{h_{1}}{2}+\frac{L_{0}}{4\left(x_{2}+L_{\mathrm{k}}\right)} \Delta h_{1}\right) ; \Delta E_{\mathrm{sp}}^{\prime}=\frac{m_{\mathrm{z}}^{\prime} \gamma_{\mathrm{z}}^{\prime} L_{\mathrm{z}}^{\prime}}{2} \Delta h_{1} \\
& \Delta E_{\mathrm{xp}}^{\prime}=m_{\mathrm{z}} \gamma_{\mathrm{z}}\left(L_{\mathrm{s}}+L_{\mathrm{k}}\right) \Delta h_{1} \quad ; \Delta E_{\mathrm{v}}^{\prime}=\frac{1}{2} F_{\mathrm{jd}} \Delta h_{1}
\end{aligned}
$$




\section{Structural characteristics of strata overlying a fully mechanized longwall face: a case study}

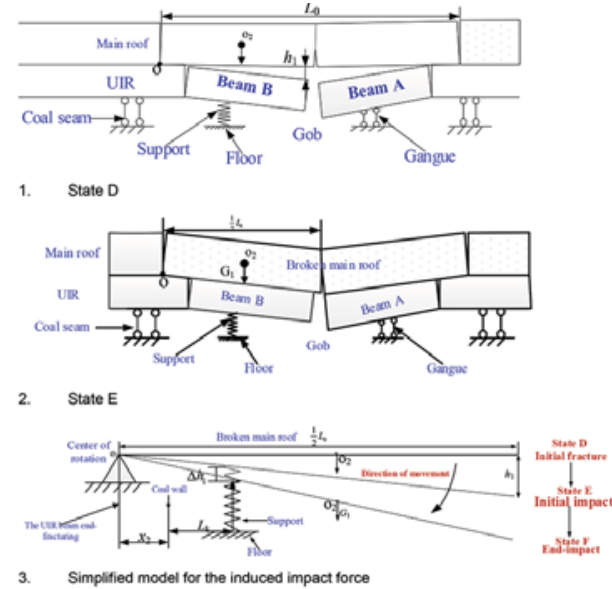

Figure 15-Structural model of main roof at stage III of model A

where $G_{1}$ is the weight of the main roof $(\mathrm{kN}), h_{1}$ is the bed separation between the main roof and UIR (m), $L_{0}$ is the first critical span of the main roof (m), and $\Delta h_{1}$ is the displacement of the roof over the shield canopy area (m).

According to the energy conservation law (David, Robert, and Jearl 2014), the impact force induced by the sudden movement of the main roof can be obtained by

$$
F_{\mathrm{jd}}=G_{2}\left(\frac{h_{1}}{\Delta h_{1}}+\frac{L_{0}}{2\left(x_{2}+L_{k}\right)}\right)+m_{2}^{\prime} \gamma_{z}^{\prime} L_{2}^{\prime}+2 m_{\mathrm{z}} \gamma_{2}\left(L_{\mathrm{s}}+L_{\mathrm{k}}\right)
$$

where $F_{\mathrm{jd}}$ is the impact load induced by the sudden movement of the main roof $(\mathrm{kN})$.

The impact load transmitted to the shield support by the LIR can be expressed as follows:

$$
\begin{aligned}
& Q_{4}=\eta \frac{m_{\mathrm{E}} \gamma_{\mathrm{E}} L_{0}}{2}\left(\frac{h_{1}}{\Delta h_{1}}+\frac{L_{0}}{2\left(x_{2}+L_{\mathrm{k}}\right)}\right)+ \\
& \eta m_{\mathrm{z}}^{\prime} \gamma_{\mathrm{z}}^{\prime} L_{\mathrm{z}}^{\prime}+2 \eta m_{\mathrm{z}} \gamma_{\mathrm{z}}\left(L_{\mathrm{s}}+L_{\mathrm{k}}\right)
\end{aligned}
$$

where $m_{\mathrm{E}}$ is the thickness of the main roof (m) and $\gamma_{\mathrm{E}}$ is the unit weight of the UIR (kN.m-3).

At this stage, the shield support external load can be expressed as follows:

$$
P_{3}=Q_{1}+Q_{3}+\frac{Q_{4}}{L_{k}}
$$

\section{Determination of working resistance from model $B$}

In model $\mathrm{B}$, the overburden movement is also divided into three stages.

\section{Stage 1}

At stage I, the shield support external load $P_{4}$ is composed of two parts: the weight of the LIR over the shield canopy area and the weight of the LIR overhangs. It can be calculated using Equation [3].

\section{Stage II}

At this stage, the shield support external load is composed of two parts: the weight of the LIR $\left(Q_{1}\right)$ and the impact load $\left(Q_{5}\right)$, induced by the periodic break of the UIR. To obtain the impact force $\left(Q_{5}\right)$ induced by the periodic movement of the UIR, a simplified model was developed (shown in Figure 16). In Figure 16, $0_{3}$ is the weight centre. Before the UIR is broken, the bed separation between the UIR and LIR is $h_{2}$. At the end of the UIR movement, the displacement of the roof over the shield canopy area increases by $\Delta h_{0}^{\prime}$. At this stage, the potential energy change of the UIR $\left(\Delta E_{\mathrm{jp}}^{\prime \prime}\right), \operatorname{LIR}\left(\Delta E_{\mathrm{sp}}^{\prime \prime}\right)$, and shield support $\left(\Delta E_{\mathrm{v}}^{\prime \prime}\right)$ can be expressed as follows:

$$
\begin{aligned}
& \Delta E_{\mathrm{jp}}^{\prime \prime}=G_{2}\left(\frac{h_{2}}{2}+\frac{L_{z}^{\prime \prime}}{2\left(x_{1}+L_{\mathrm{k}}\right)} \Delta h_{0}^{\prime}\right) ; \Delta E_{\mathrm{sp}}^{\prime \prime}=\frac{m_{2}^{\prime} \gamma_{2}^{\prime} L_{z}^{\prime}}{2} \Delta h_{0}^{\prime} \\
& \Delta E_{\mathrm{v}}^{\prime \prime}=\frac{1}{2} F_{\mathrm{sd}}^{\prime} \Delta h_{0}^{\prime}
\end{aligned}
$$

where $G_{2}$ is the LIR weight in model B $(\mathrm{kN}), L_{z}^{\prime \prime}$ is the periodic broken length of the LIR (m), and $F_{s d}^{\prime}$ is the impact force induced by movement of the UIR $(\mathrm{kN})$.

After the movement of the UIR, the change in potential energies of the UIR and LIR is transformed into elastic potential energy of the shield support. According to the energy conservation law (David, Robert, and Jearl. 2014), the impact force $F_{S d}^{\prime}$ induced by the sudden movement of the UIR can be obtained by:

$$
F_{\mathrm{sd}}^{\prime}=G_{2}\left(\frac{h_{2}}{\Delta h_{0}^{\prime}}+\frac{L_{z}^{\prime \prime}}{x_{1}+L_{\mathrm{k}}}\right)+m_{\mathrm{z}}^{\prime} \gamma_{\mathrm{z}}^{\prime} L_{\mathrm{z}}^{\prime \prime}
$$

The impact force $Q_{5}$ transmitted to the shield support can be expressed as:

$$
Q_{5}=\eta m_{z}^{\prime} \gamma_{z}^{\prime} L_{z}^{\prime \prime}\left(\frac{h_{2}}{\Delta h_{0}^{\prime}}+\frac{L_{z}^{\prime \prime}}{x_{1}+L_{\mathrm{k}}}\right)+2 \eta m_{\mathrm{z}} \gamma_{\mathrm{z}}\left(L_{\mathrm{s}}+L_{\mathrm{k}}\right)
$$

At this stage, the shield support external load P5 can be expressed as:

$$
P_{5}=Q_{1}+\frac{Q_{5}}{L_{\mathrm{k}}}
$$

\section{Stage III}

At this stage, the shield support external load $P_{6}$ is composed of three parts: the weight of the LIR, $Q_{1}$; the load force induced by the movement of the UIR, $Q_{3}$; and the impact force induced by the movement of the main roof, $Q_{6}$. The weight of the LIR, $Q_{1}$, and the load force induced by the movement of the UIR, $Q_{3}$, can be calculated using Equations [3] and [4], respectively.

To obtain the impact force $\left(Q_{6}\right)$ induced by the periodic movement of the UIR, a simplified model was developed (Figure 17). In Figure 17, $0_{4}$ is regarded as the broken main roof. The change in potential energy of the main roof $\left(\Delta E_{\mathrm{jp}}^{\prime \prime}\right)$, UIR $\left(\Delta E_{\mathrm{sp}}^{\prime \prime \prime}\right)$, LIR $\left(\Delta_{\mathrm{xp}}^{\prime \prime \prime}\right)$, and shield support $\left(\Delta_{\mathrm{v}}^{\prime \prime \prime}\right)$ can be expressed as:

$$
\begin{aligned}
& \Delta E_{\mathrm{jp}}^{\prime \prime}=G_{3}\left(\frac{h_{1}^{\prime}}{2}+\frac{L_{1}}{2\left(x_{2}^{\prime}+L_{k}\right)} \Delta h_{1}^{\prime}\right) ; \quad \Delta E_{\mathrm{sp}}^{\prime \prime \prime}=m_{\mathrm{z}}^{\prime} \gamma_{\mathrm{z}}^{\prime} L_{\mathrm{z}}^{\prime \prime} \Delta h_{1}^{\prime} \\
& \Delta E_{\mathrm{xp}}^{\prime \prime \prime}=m_{\mathrm{z}} \gamma_{\mathrm{z}}\left(L_{\mathrm{s}}+L_{\mathrm{k}}\right) \Delta h_{1}^{\prime} ; \quad \Delta E_{\mathrm{v}}^{\prime \prime \prime}=\frac{1}{2} F_{\mathrm{jd}}^{\prime} \Delta h_{1}^{\prime}
\end{aligned}
$$

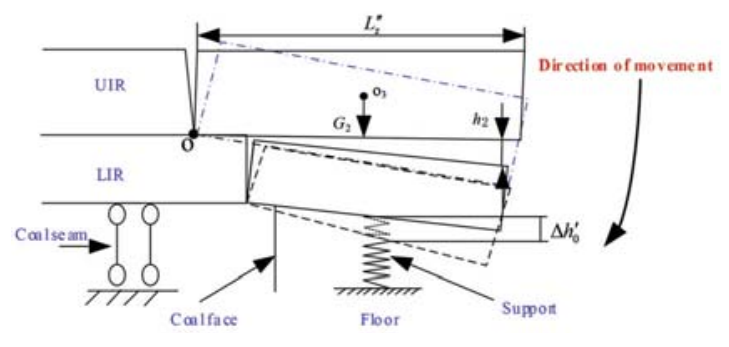

Figure 16-Simplified model of the impact force induced by movement of UIR at stage II of model B 


\section{Structural characteristics of strata overlying a fully mechanized longwall face: a case study}

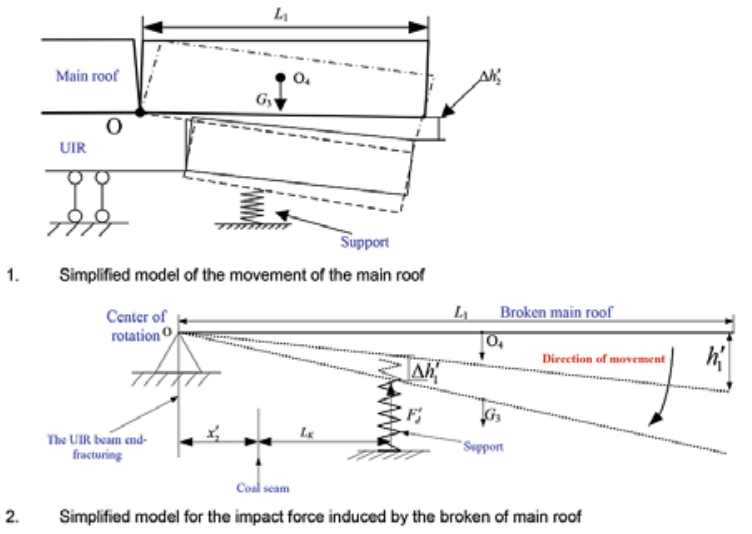

Figure 17-Simplified model of the impact force induced by movement of the main roof at stage III of model $B$

where $G_{3}$ is the weight of the LIR in model B $(k \mathrm{~N}), h_{1}^{\prime}$ is the bed separation between the UIR and main roof in model $B$ (m), $L_{1}$ is the periodic broken length of the main roof $(\mathrm{m})$, $\Delta h_{1}^{\prime}$ is the displacement of main roof in model B (m), $x_{2}^{\prime}$ is the horizontal distance from the main roof beam endfracturing to the longwall face in model B (m), and $F_{\text {jd }}^{\prime}$ is the impact force induced by the movement of the main roof in model B.

According to the energy conservation law (David, Robert, and Jearl. 2014), the impact force $F_{\text {jd }}^{\prime}$ induced by the movement of the main roof in model B can be expressed as:

$$
F_{\text {jd }}^{\prime}=G_{3}\left(\frac{h_{1}^{\prime}}{\Delta h_{1}^{\prime}}+\frac{L_{1}}{x_{2}^{\prime}+L_{\mathrm{k}}}\right)+2 m_{\mathrm{z}}^{\prime} \gamma_{\mathrm{z}}^{\prime} L_{\mathrm{z}}^{\prime \prime}+2 m_{\mathrm{z}} \gamma_{\mathrm{z}}\left(L_{\mathrm{s}}+L_{\mathrm{k}}\right)
$$

The impact force $Q_{5}$ transmitted to the shield support can be expressed as:

$$
F_{\mathrm{jd}}^{\prime}=G_{3}\left(\frac{h_{1}^{\prime}}{\Delta h_{1}^{\prime}}+\frac{L_{1}}{x_{2}^{\prime}+L_{\mathrm{k}}}\right)+2 m_{\mathrm{z}}^{\prime} \gamma_{\mathrm{z}}^{\prime} L_{\mathrm{z}}^{\prime \prime}+2 m_{\mathrm{z}} \gamma_{\mathrm{z}}\left(L_{\mathrm{s}}+L_{\mathrm{k}}\right)
$$

At this stage, the shield support external load $P_{6}$ can be expressed as:

$$
P=\max \left(P_{1}, P_{2}, P_{3}, P_{4}, P_{5}, P_{6}\right)
$$

In conclusion, the abovementioned two models should be considered when calculating the shield support external load when using the SGMHLW method. Therefore, the working resistance of the shield support can be expressed as:

$$
P_{6}=Q_{1}+Q_{3}+\frac{Q_{6}}{L_{\mathrm{k}}}
$$

\section{Justification and application}

Based on the stratigraphy of panel 311101, the working resistance of the shield supports can be calculated. As shown in Figure 1, the LIR of panel 311101 is sandy mudstone with a height of $4.0 \mathrm{~m}$, which will cave and fall into the goaf following the advance of the coal extraction and shield support. The UIR of this panel is siltstone less than $7.0 \mathrm{~m}$ thick. The main roof is composed mainly of fine sandstone and sandy mudstone, and its thickness is $30.5 \mathrm{~m}$. Based on experience in mining engineering, the LIR unit weight is $22.5 \mathrm{kN} / \mathrm{m}^{3}$ and its bulk factor $K_{\mathrm{A}}$ is 1.2 . The UIR and main roof unit weights are 22.8 and $23.8 \mathrm{kN} / \mathrm{m}^{3}$, respectively.
Field experience shows that cave-in events occur so that a roof weighting is placed on the longwall shields. The variations in response of the longwall shields can be used to predict the critical spans or breaking length of overlying strata. According to the analysis of the shield support TWAR (as shown in Figure 5), the increasing rate of resistance can be divided into three main types which could refer to the breaking of the LIR, UIR, and main roof. Therefore, the critical spans of the LIR $\left(L_{\mathrm{Z}}\right)$, UIR $\left(L_{\mathrm{Z}}^{\prime}\right)$, and main roof $\left(L_{0}\right)$ in model A are 23.5, 38.2, and $60.0 \mathrm{~m}$, respectively. The critical spans of the UIR $\left(L_{\mathrm{Z}}^{\prime \prime}\right)$ and main roof $\left(L_{1}\right)$ in model B are 16.2 and $34.7 \mathrm{~m}$, respectively. A laser measuring instrument was installed at the end of the support of the working face to measure the rear overhang of the LIR $\left(L_{\mathrm{S}}\right)$, which was determined to be approximately $2.0 \mathrm{~m}$. According to the support parameters, the shield canopy length is approximately 5.0-6.4 m. Field investigations show that in model $\mathrm{A}, \Delta h_{1}$ and $\Delta h_{1}$ are 0.35 and $0.20 \mathrm{~m}$, respectively. In model B, $\Delta h_{0}^{\prime}$ and $\Delta h_{1}^{\prime}$ are 0.25 and $0.65 \mathrm{~m}$, respectively. A multiposition borehole extensometer was installed in panel 311101. For each extensometer, three anchors were installed in the LIR, UIR, and main roof to measure the displacements. The field measurements showed that $h_{1}=0.2 \mathrm{~m}$ and $h_{1}^{\prime}=$ $0.1 \mathrm{~m}$.

According to the three types of structures that exist in panel 311101 and the equations presented in the previous sections, the working resistance for each of the three stages was calculated, and the results are reported in Table II. At stage II of models A and B, the working resistances of the shield support are 4720 and $4517 \mathrm{kN}$, and the corresponding dynamic load coefficients are 2.2 and 2.4, respectively. At stage III of models A and B, i.e. when the main roof undergoes violent movement, the working resistances of the shield support are 12782 and $10398 \mathrm{kN}$, and the corresponding dynamic load coefficients are 2.7 and 2.3, respectively. Therefore, the working resistance of the shield support with the advance of the longwall face is 1.141 MPa (12 $782 \mathrm{kN})$, according to Equation [23].

Table III lists the estimated working resistance of the shield support using the equations provided by Song (1988) and Qian et al. (2010). As shown in Table III, the measured working resistance of panel 311101 is approximately $12084 \mathrm{kN}$, while the working resistances estimated by using the equations provided by Song (1988) and Qian et al. (2010) were 7294.1 and $8500.4 \mathrm{kN}$, respectively, which are much lower than those obtained from the measurements in this study. However, the working resistance estimated using Equation [23] is $12782 \mathrm{kN}$, which is very close to the measured value. Obviously, the methods that Song (1988) and Qian et al. (2010) provide cannot be used for a SGMHLW operation. Thus, the $6.0 \mathrm{~m}$ height chock shields with working resistance of $13000 \mathrm{kN}$ were used in the next panel, that is, panel 311102 of the Gaojialiang coal mine.

\section{Conclusions}

In China, the SGMHLW mining method has been successfully practiced in the Ordos coalfield. To understand the strata behaviour induced using the SGMHLW method, an in situ investigation and theoretical research were conducted on panel 311101 of the Gaojialiang mine. The results presented in this paper are summarized as follows.

1. With the advance of the longwall face, the SLPMS of 


\section{Structural characteristics of strata overlying a fully mechanized longwall face: a case study}

\begin{tabular}{|c|c|c|}
\hline \multicolumn{3}{|c|}{$\begin{array}{l}\text { Table II } \\
\text { Theoretical value of support resistance }\end{array}$} \\
\hline & Model A (kN) & Model B (kN) \\
\hline $\begin{array}{l}\text { Stage I } \\
\text { Stage II } \\
\text { Stage III }\end{array}$ & $\begin{array}{c}2153 \\
4720 \\
12782\end{array}$ & $\begin{array}{c}1875 \\
4517 \\
10398\end{array}$ \\
\hline
\end{tabular}

Table III

\section{Comparison between working resistances calculated by various methods}

\begin{tabular}{|l|c|c|c|c|}
\hline & $\begin{array}{c}\text { Measured } \\
\text { (this investigation) }\end{array}$ & $\begin{array}{c}\text { Calculated } \\
\text { (this investigation) }\end{array}$ & $\begin{array}{c}\text { Song } \\
\mathbf{( 1 9 8 8 )}\end{array}$ & $\begin{array}{c}\text { Qian } \\
\text { (2010) }\end{array}$ \\
\hline $\begin{array}{l}\text { Working } \\
\text { resistance }(\mathrm{kN})\end{array}$ & 12084 & 12782 & 7294.1 & 8500.4 \\
\hline Difference (\%) & - & 5.8 & -39.6 & -29.7 \\
\hline
\end{tabular}

Note: Difference with regard to working resistance measured from SLPMS

the shield support progressed in three stages: slow, rapid, and high-speed growth. In addition, the shield suffered from two impact loadings induced by the overburden movement. The numerical simulation also confirmed that the progressive failure of the strata could be divided in three stages.

2. Based on the data obtained from the in situ investigation and numerical simulation, a simplified theoretical model was built to describe the structural characteristics of the overlying strata. In this model, the progressive failure of the overlying strata was divided into three stages. In addition, the working resistance of the shield was determined at every stage, and then a reasonable working resistance was identified for the shield support under SGMHLW conditions. The reasonable working resistance is defined as $P=\max \left(P_{1}, P_{2}, P_{3}, P_{4}, P_{5}, P_{6},\right)$. The appropriate working resistance for the $6.0 \mathrm{~m}$ height chock shields of the longwall face of panel 311101 in the Bayangaole coal mine was determined at $12782 \mathrm{kN}$.

\section{Acknowledgments}

This study was supported by National Key R\&D Program of China (2018YFC0604703), the National Natural Science Foundation of China (No. 51574154, 51274133, 51474137, 51574155), the Shandong Province Science and Technology Development Plan, item (2014GSF120002), and the Tai'shan Scholar Engineering Construction Fund of the Shandong Province of China.

\section{References}

Alehossein, H. and Poulsen, B.A. 2010. Stress analysis of longwall top coal caving. International Journal of Rock Mechanics and Mining Sciences, vol. 47, no. 1. pp. 30-41.

David, H., RoBert, R., and Jearl, W. 2014. Principles of Physics. 10th edn. Wiley, New York.

BATCHLER, T. 2017. Analysis of the design and performance characteristics of pumpable roof supports. International Journal of Mining Science and Technology, vol. 27, no. 1. pp. 91-99.

COULTHARD, M.A. 1999. Applications of numerical modelling in underground mining and construction. Geotechnical and Geological Engineering, vol. 17 , no. 3. pp. 373-385

GonG, P.L. and Jin, Z.M. 2008. Mechanical model study on roof control for fullymechanized coal face with large mining height. Chinese Journal of Rock Mechanics and Engineering, vol. 27, no. 1. pp. 193-198 [in Chinese]

GHose, A.K. and DuTTA, D. 1987. A rock mass classification model for caving roofs. Geotechnical and Geological Engineering, vol. 5, no. 3. pp. 257-271.

GiLBRIDE, L.J., Richardson A.M., and AGAPITO J.F.T. 1998. Use of block models for longwall shield capacity determinations. International Journal of Rock Mechanics and Mining Sciences, vol. 35, no. 4-5. pp. 425-426.

HENDERSON, P.G. 1980. Experience in longwall mining at Coalbrook Collieries. Journal of the South African Institute of Mining and Metallurgy, vol. 80, no. 1. pp. 22-33.

IsLAVATH, S.R, DeB, D., and Kumar, H. 2016. Numerical analysis of a longwall mining cycle and development of a composite longwall index. International Journal of Rock Mechanics and Mining Sciences, vol. 89. pp. 43-54.

Ju, J.F. and Xu, J.L. 2013. Structural characteristics of key strata and strata behaviour of a fully mechanized longwall face with $7.0 \mathrm{~m}$ height chocks. International Journal of Rock Mechanics and Mining Sciences, vol. 58, no. 1. pp. 46-54.

JiAnG, L.S., SAINoKI, A., and Mitri, H.S. 2016, Influence of fracture-induced weakening on coal mine gateroad stability. International Journal of Rock Mechanics and Mining Sciences, vol. 88. pp. 307-317. doi: 10.1016/j.ijmms.2016.04.017

Lawson, H.E., Douglas, T., Larson, M.K., and HabTe, A. 2017, Effects of overburden characteristics on dynamic failure in underground coal mining. International Journal of Mining Science and Technology, vol. 27, no. 1. pp. 121-129.

Ning, J.G., LiU, X.S., TAN, Y.L., Zhang M., and Zhang L.S. 2014, Fracture structure model of weakly cemented roof in shallow seam. Journal of Mining and Safety Engineering, vol. 31, no. 4. pp. 569-574 [in Chinese].

Ning, J.G, WANG, J., TAN, Y.L., ZHANG L.S., and Bu T.T. 2017, In situ investigations into mining-induced overburden failures in close multipleseam longwall mining: A case study. Geomechanics and Engineering, vol. 12 , no. 4. pp. 814-820.

Peng, S.S., Li, H.M., and Zhou, Y. 2015. Ground Control in the Ordos Coal Field. China Science Press, Beijing.

Peng, S.S. and ChIAng H.S. 1984. Longwall Mining. Wiley, New York.

Prusek, S., PŁonKa, M., and WalenteK, A. 2016. Applying the ground reaction curve concept to the assessment of shield support performance in longwall faces. Arabian Journal of Geosciences, vol. 9, no. 3. pp. 1-15.

SMART, B.G.D. and REDFERN, A. 1986. The evaluation of powered support from geological and mining practice specifications information. Proceedings of the 27th US Symposium on Rock Mechanics (USRMS),Tuscaloosa, Alabama, 23-25 June 1986. American Rock Mechanics Association, Alexandria, VA. pp. 367-377.

SoNG, Z.Q. 1988. Practical ground pressure control. China University of Mining and Technology Press, Xuzhou.

Sofianos, A.I. 1996. Analysis and design of an underground hard rock voussoir beam roof. International Journal of Rock Mechanics and Mining Sciences, vol. 32 , no. 2 . pp. $153-166$.

SinGH, R., and SinGH, T.N. 1999. Investigation into the behaviour of a support system and roof strata during sublevel caving of a thick coal seam. Geotechnical and Geological Engineering, vol. 17, no. 1. pp. 21-35.

ShabANimASHCOOL, M., Jing, L., and Li, C.C. 2014. Discontinuous modelling of stratum cave-in in a longwall coal mine in the arctic area. Geotechnical and Geological Engineering, vol. 32, no. 5. pp. 1239-1252.

TRUEMAN, R., LyMAN, G., and CockeR, A. 2009. Longwall roof control through a fundamental understanding of shield-strata interaction. International Journal of Rock Mechanics and Mining Sciences, vol. 46, no. 2. pp. 371-380.

TAN, Y.L., LIU X.S. Ning, J.G., and Lu Y.W. 2017. In situ investigations on failure evolution of overlying strata induced by mining multiple coal seams. Geotechnical Testing Journal, vol. 40, no. 2. pp. 244-257.

Verma, A.K. and DeB, D. 2013. Numerical analysis of an interaction between hydraulic-powered support and surrounding rock strata. International Journal of Geomechanics, vol. 13, no. 2. pp. 181-192.

YASITLI, N.E. and UnVER, B. 2005. 3D numerical modeling of longwall mining with top-coal caving. International Journal of Rock Mechanics and Mining Sciences, vol. 42, no. 2. pp. 219-235.

Yu, B., ZHAo, J., and KuAnG, T.J. 2015. In situ investigations into overburden failures of a super-thick coal seam for longwall top coal caving. International Journal of Rock Mechanics and Mining Sciences, vol. 4, no. 78 . pp. $155-162$.

Yu, B., ZHAO, J., and XIAO, H.T. 2017. Case study on overburden fracturing during longwall top coal caving using microseismic monitoring. Rock Mechanics and Rock Engineering, vol. 50, no. 2. pp. 507-511.

UNVER, B. and YASITLI, N.E. 2006. Modelling of strata movement with a special reference to caving mechanism in thick seam coal mining. International Journal of Coal Geology, vol. 66, no. 4. pp. 227-252.

ZHANG D.S., FAN G.W., and MA L.Q. 2011. Aquifer protection during longwall mining of shallow coal seams: a case study in the Shendong Coalfield of China. International Journal of Coal Geology, vol. 86, no. 2. pp. 190-196. 